\title{
Finite Element Simulation of Deep Excavation Failures
}

\author{
Ching Hung • Hoe I. Ling • Victor N. Kaliakin
}

Accepted: 19 June 2014 / Published online: 8 July 2014

(C) Springer New York 2014

\begin{abstract}
Deep excavations play an increasingly greater role in the development of urban transportation infrastructure facilities such as subway systems and underground space. This paper presents the results of finite element simulations of two deep excavations in soft cohesive soils involving collapse. An enhanced bounding surface soil model characterizes the cohesive soils. The model is anisotropic and is formulated with a non-associative flow rule, but can be degenerated to an isotropic model with associative flow. The results of the excavation simulations give insight into the ground response in terms of lateral wall deflections, ground surface settlements, wall bending moments, and strut force developments. Anisotropic and isotropic versions of model showed differences in simulated results. The insignificant difference in results between the associative and non-associative versions of enhanced bounding surface model is illustrated, but it is expected that, in general, the use of non-associative flow rule will provide a more realistic simulation.
\end{abstract}

Keywords Finite element simulation · Deep excavation $\cdot$ Cohesive soil

\section{Introduction}

Deep excavations in urban areas are often located in close proximity to existing buildings or other critical components of the infrastructure. This imposes rather stringent requirements on the associated deformations so that they do not adversely affect adjacent structures. A successful deep excavation is thus one that possesses adequate stability and minimizes excavation-induced deformations. This is not, however, an easy

\footnotetext{
C. Hung $\cdot$ H. I. Ling $(\bowtie)$

Department of Civil Engineering and Engineering Mechanics, Columbia University, 500 West 120th Street, New York, NY 10027, USA

e-mail: ling@civil.columbia.edu

C. Hung

e-mail: ch2532@columbia.edu

V. N. Kaliakin

Department of Civil and Environmental Engineering, University of Delaware, Newark, DE 19716, USA

e-mail: kaliakin@udel.edu 
goal to achieve since walls or other structural elements are embedded into soft soils. The ground surface behind such walls should not settle uncontrollably so as not to damage surrounding structures.

The complex nature of deep excavations precludes their analysis using simple analytical methods. Instead, studies of such excavations have been either based on empirical observations or have been modeled mathematically and analyzed using a finite element or finite difference computer program.

One of the key aspects of such mathematical models is the characterization of the soft cohesive soils present at the excavation site [3, 8, 25]. Various constitutive relations, possessing different levels of sophistication (e.g., [6, 7, 15, 21-23, 28, 29]), have been used to characterize such soils. Relatively simple constitutive models are typically unable to accurately simulate the response associated with deep excavations. Thus, of particular interest to the present discussion are elastoplastic models based on the concept of a bounding surface in stress space $[4,5]$. In the past, such models have been shown to realistically simulate deep excavations involving soft cohesive soils [7, 28].

In general, the study of failures associated with deep excavations provides insight into the possible causes of such failures and may lead to improved design methodologies. However, in many instances, field instrumentation data are either not well documented or are unavailable due to damage (deep excavation failures typically occur without warning), recording errors, or pending litigation. In addition, numerical methods suffer from the drawback of being unable to conduct analyses in postfailure regime, unless issues such as strain softening and shear banding (e.g., [27]) are considered for the soil and structural elements. The study of failed deep excavations is thus not without limitations.

This paper presents technical information related to two case histories of deep excavation in Taipei. The sites are modeled and simulated using the small strain finite element method. The soft cohesive soils found at these sites are characterized by an enhanced anisotropic bounding surface model with associative [17] and nonassociative $[11,12]$ flow rules that is implemented into the PLAXIS computer program [26] as part of this study. The results of the simulations are critically assessed with relation to field observations.

\section{Description of Deep Excavation Sites}

Two case histories of collapsed deep excavation sites in Taipei city (see Fig. 1a) are considered in this paper, namely, the Shilin Li-Ba Bailaohui site (site 1) and the Beitou Shihpai Zi-Qiang Street site (site 2). The soil at the two failure sites was primarily soft Taipei silty clay. These two sites have been discussed in Hsieh et al. [9] for base heave analyses.

\section{Shilin Li-Ba Bailaohui (site 1)}

The excavation site was approximately rectangularly shaped with two width session of 26 and $15 \mathrm{~m}$, and length of $100 \mathrm{~m}$. It was bounded by the intersection of Jihe and section 4 of Chengde roads. It is close to the current Jiantan Station on the Metro Red 


\section{a}

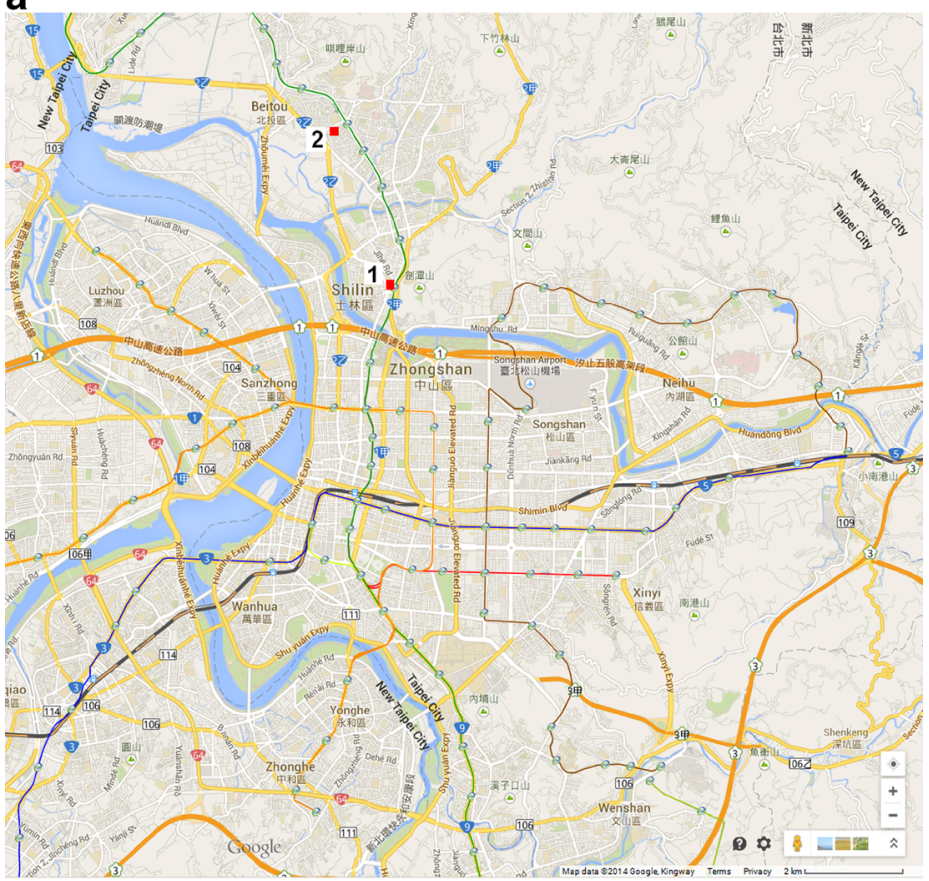

b

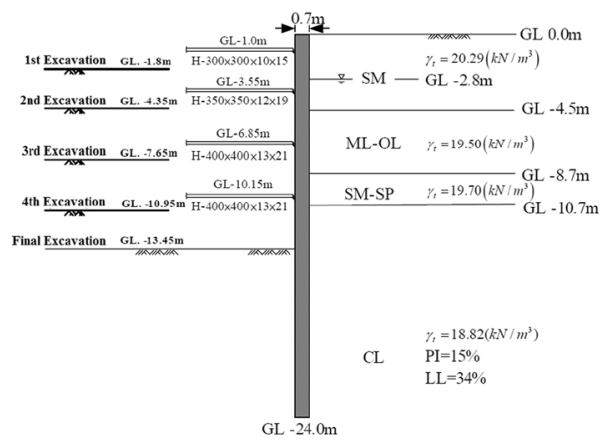

to $\mathrm{GL}-44.7 \mathrm{~m}$

C

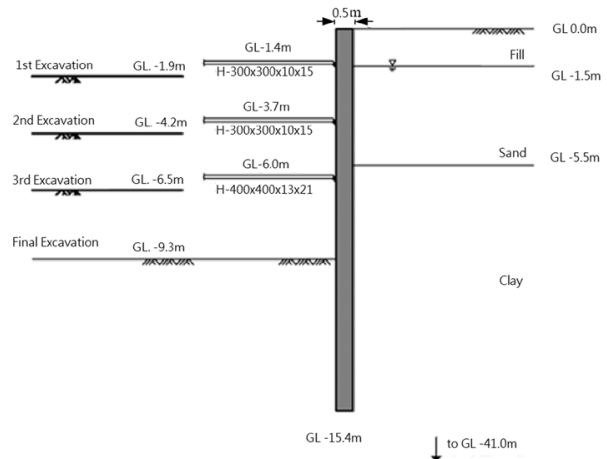

Fig. 1 a Locations of excavation sites in the Taipei area (after Google maps), b ground profile and crosssection of site 1 (after [20]), and $\mathbf{c}$ ground profile and cross-section of site 2 (after [19]) 
Line. Figure $1 \mathrm{~b}$ shows an averaged profile of the subsurface stratigraphy of site 1 . The soil geology around the site was known as TK3, which shared the characteristics of land reclaimed from the sea. The soil layers included a fill layer at the top, sand deposits, and a thick Taipei clay deposit. The final depth of excavation was $13.45 \mathrm{~m}$ below the ground surface.

On September 26, 1993, $2.5 \mathrm{~h}$ after completion of the construction activity, the site suddenly collapsed. The major soil movement lasted for $2 \mathrm{~min}$ and affected an area having a width of $40 \mathrm{~m}$ and a length of $132 \mathrm{~m}$. The main evidence of collapse was excessive ground deformations and failure of the supporting system. Liu [19], PCC [24], and Liao and $\mathrm{Ou}$ [20] reported certain details pertaining to site 1 following the aforementioned failure.

Due to the lack of laboratory test data for the soils at this site, the soil properties of nearby Cheng-De Park were assumed. Cheng-De Park is $200 \mathrm{~m}$ from the failure site and had very similar soil stratigraphy, according to the geological map of the Central Geological Survey, Ministry of Economic Affairs (MOEA).

\section{Beitou Shipai Zi-Qiang Street (Site 2)}

The excavation site was approximately rectangularly shaped, with a width of $12.3 \mathrm{~m}$ and a length of $45 \mathrm{~m}$. It was bounded by the intersection of section 1 of Shipai and section 2 of Zhiyuan First roads. Figure 1c shows an averaged profile of subsurface stratigraphy for site 2 . The soil geology around the site was also TK3. The soil layers at the site included a fill layer at the top, sand deposits, and a thick Taipei clay deposit. The natural water content of the Taipei clay deposit at site 2 was relatively high (38-44.1\%). The final depth of excavation was $9.3 \mathrm{~m}$ below the ground surface.

In the early morning of February 28, 1993, 1 day after reaching the final depth of excavation, the site collapsed. Excessive ground deformations, especially settlements behind the retaining wall, were recorded. The ground deformations around the site damaged an adjacent four-story building, as well as streets and utilities.

In light of difficulties in obtaining laboratory test samples for site 2, the soil properties from the Taipei City Shipai Junior High School were assumed. Although this school was located $500 \mathrm{~m}$ away from site 2, its soil stratigraphy is similar to that for the site. This assumption was attributed to the geological map of the Central Geological Survey, MOEA.

\section{Finite Element Modeling of Excavation Sites}

PLAXIS was used in the analysis. Both sites were modeled as two-dimensional solution domains and analyzed assuming plane strain conditions. Although deep excavations are inherently three-dimensional problems, the lack of sufficient spatial variations of soil profiles and construction details necessitated the two-dimensional analyses.

In all simulations, the displacements and stresses of the solid phase were assumed to be coupled to changes in excess pore pressure according to generalized Biot's theory [1]. Considering the fact that either there were very small changes in groundwater level as excavation activities proceeded or dewatering of the construction sites 
was performed using shallow sumps within the excavation, practical results could only be obtained by assuming the initial groundwater level behind the excavation throughout the construction. In general, finite element analyses of deep excavations that take into account changes in groundwater level during construction are rare, as this is a non-trivial undertaking.

Since both sites were essentially geometrically symmetrical in the plane of analysis, the solution domains consisted of only one half of the entire excavation. Figure $2 \mathrm{a}$ and $\mathrm{b}$ shows typical meshes for sites 1 and 2, respectively, where half widths of excavation were 13 and $6.15 \mathrm{~m}$. Because of the aforementioned symmetry of the solution domain, horizontal displacements were prevented at nodes located along its right boundary.

The extent of the finite element mesh behind the wall was taken to be approximately four times larger than the final depth of excavation. This was done to avoid possible boundary effects on the results of deformations and pore pressure. The bottom of the mesh extended to the rock, 44.7 and $41.0 \mathrm{~m}$ from the ground surface for sites 1 and 2, respectively. Mesh sensitivity studies indicated that any larger distances did not significantly affect the simulated ground deformations and wall displacements. Horizontal displacements were thus restrained at nodes located along the left boundary of the solution domain. Finally, both horizontal and vertical displacements were restrained at nodes along the bottom boundary.

The groundwater flow regimes at construction sites are difficult to know with great certainty. However, due to symmetry, flow of pore water must be prevented at nodes located along the right boundary of the solution domain. In addition, since the bottom and left boundaries were considered to be "far field," constant flow conditions (i.e., zero fluid flux) were specified at nodes located along these boundaries.

The various soil layers were discretized using six-node triangular continuum elements (quadratic in displacement; linear in pressure). PLAXIS has the option of using 15-node elements, but this was found to impede convergence in the analyses of sites 1 and 2. The struts, slabs, and diaphragm walls were discretized using one-dimensional beam elements. Mesh sensitivity analyses were performed before deciding on the final mesh densities used in the deep excavation simulations. The overall meshes for the analysis of both sites consisted of approximately 700 elements, with about 4,800 nodal

a

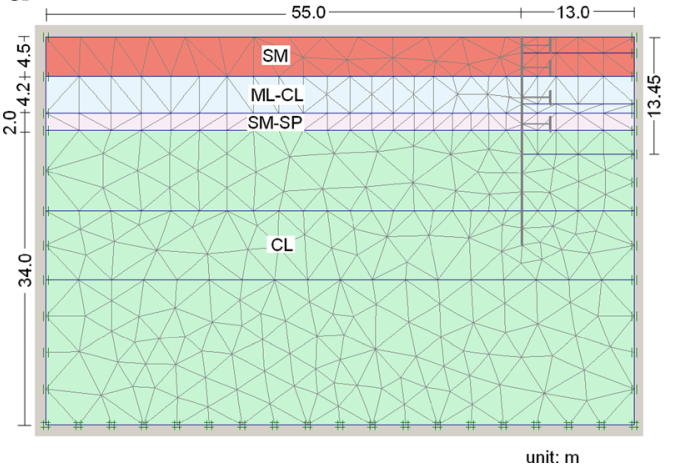

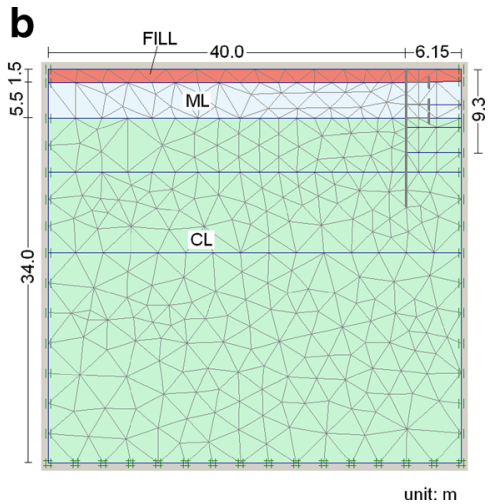

Fig. 2 Finite element mesh in PLAXIS (units: $\mathrm{m}$ ): $\mathbf{a}$ site 1 and $\mathbf{b}$ site 2 
Table 1 Bounding surface model parameter values used to characterize Taipei clay

\begin{tabular}{lll}
\hline Parameter & $\begin{array}{l}\text { Isotropic version } \\
\text { of model }\end{array}$ & $\begin{array}{l}\text { Anisotropic version } \\
\text { of model }\end{array}$ \\
\hline$\lambda$ & 0.17 & 0.17 \\
$\kappa$ & 0.02 & 0.02 \\
$\nu$ & 0.30 & 0.30 \\
$M_{\mathrm{c}}, M_{\mathrm{e}}$ & $1.3,0.97$ & $1.11,0.92$ \\
$N_{\mathrm{c}}, N_{\mathrm{e}}$ & $1.57,1.27$ & $1.05,1.05$ \\
$w$ & 1.0 & 38.0 \\
$c$ & 0.65 & 0.30 \\
$s_{\mathrm{p}}$ & 2.0 & 3.0 \\
$h$ & 1.0 & 5.0 \\
\hline
\end{tabular}

degrees of freedom. It has been verified that the use of higher mesh densities increased the computational effort without significantly affecting the results of the simulations.

\section{Material Characterizations and Parameters}

The Taipei silty clay layers at both sites were characterized by the enhanced bounding surface model with both associative and non-associative flow rules. Although the model is formulated for anisotropically consolidated cohesive soils, it is easily reduced to the isotropic version of the model [14]. Thus, three versions of bounding surface model were used. The formulation and predictive capabilities of the enhanced anisotropic bounding surface model with associative and non-associative flow rules have been previously documented [10, 12, 17].

The model requires values of 11 material parameters as well as the initial state states. $\lambda, \kappa, M_{\mathrm{c}}, M_{\mathrm{e}}, G, N_{\mathrm{c}}$, and $N_{\mathrm{e}}$, are classified as traditional parameters, whereas $w, c, s$, and $h$ are the bounding surface parameters. $\lambda$ (compression index) and $\kappa$ (recompression index) represent the slope of the normal compression line and the slope of the swelling or recompression line in $e-\ln (p)$ space. The elastic shear modulus $G$ represents the initial slope of the shear stress-shear strain curve. $\nu$ is Poisson's ratio. $M_{\mathrm{c}}$ and $M_{\mathrm{e}}$ (frictional constants at critical state) are the surface configuration parameters for the plastic potential surface in the compression and extension domains, respectively. $N_{\mathrm{c}}$ and $N_{\mathrm{e}}$ (measure of shear strength) are the surface configuration parameters for the bounding surface. $w$ is a classical anisotropic elastoplastic parameter that describes the rate of evolution of anisotropy. $c$ (the projection center parameter) specifies the center of the projection (or the center of homology) for the elastic nucleus and the bounding surface and indirectly specifies the location of the elastic nucleus. The parameters $s$ and $h$ describe the distribution of plastic modulus within the bounding surface; the parameter $s$ specifies the size of the elastic nucleus and $h$ determines how fast the plastic modulus changes from infinite to the bounding plastic modulus when the stress point gradually moves from the boundary of the elastic nucleus to the bounding surface.

Bounding surface models are not available in the PLAXIS computer program [26]. Consequently, the model was implemented into PLAXIS. This is done by compiling 
Fig. 3 Simulations of Taipei silty clay anisotropic behavior: a stress paths, b stress-strain response, normally consolidated, and c stress-strain response, overly consolidated a

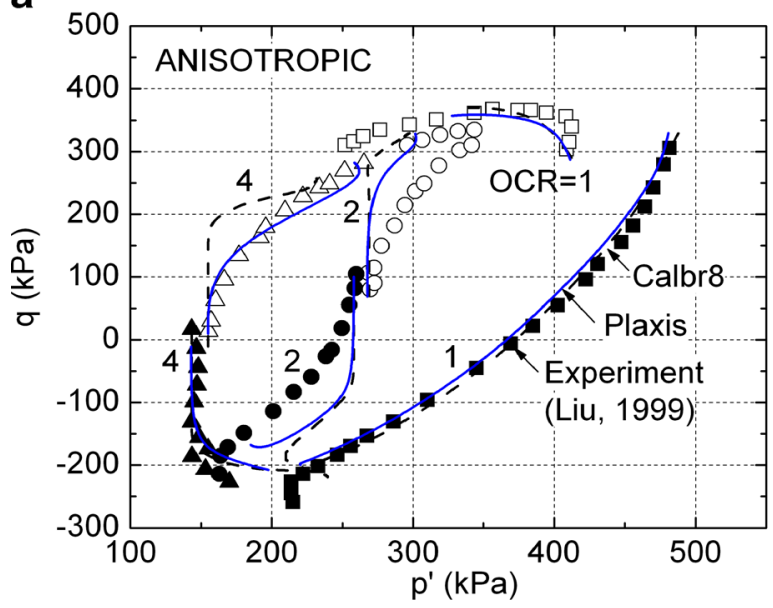

b
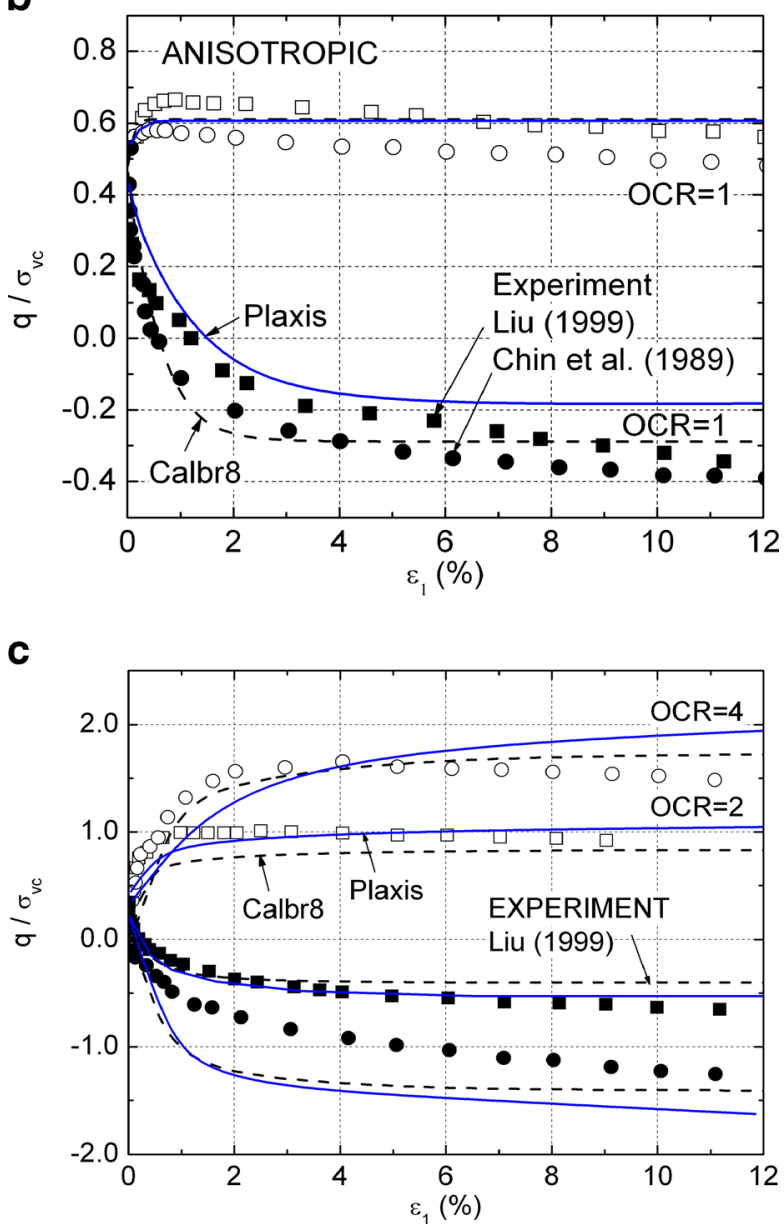
the set of subroutines associated with the model as a Dynamic Link Library, which was then linked with PLAXIS prior to program execution. The implementation of soil model was verified by simulating the response of several "benchmark" soils. These simulations were compared to earlier ones obtained using the CALBR8 computer program [13]. CALBR8 was written to assess the characteristics of various constitutive models for soils. It performs a three-dimensional analysis under either drained or undrained conditions, with different stress paths, using combinations of six applied stress or strain components.

Hung et al. [10] calibrated the model parameters required to simulate Taipei silty clay (Table 1). The response of both soils was simulated under axisymmetric triaxial compression and extension conditions at various overconsolidation ratios. Figure $3 \mathrm{a}-\mathrm{c}$ compares bounding surface model simulations (employing a non-associative flow rule) with experimental results for anisotropically consolidated specimens of Taipei silty clay. Reasonable agreement was obtained in the simulations.

The initial states of the Taipei silty clay were anisotropic. The initial stresses, void ratios, and other parameters were obtained from the documentation associated with sites 1 and 2 given by Liu [19]. The OCR varies between 1.75 and 1.0 with depth in the clay layer at the sites. The overconsolidation was expressed through an effective preconsolidation stress $p_{\mathrm{o}}^{\prime}$ as shown in Tables 2 and 3 for sites 1 and 2, respectively. The $K_{\mathrm{o}}$ value obtained from experiments was approximately 0.5 for both sites. Due to the lack of suitable laboratory data, the other top soil layers at the two sites were characterized using simple elastoplastic constitutive models obeying the Mohr-Coulomb failure criteria with an angle of internal friction $\varphi^{\prime}$. To improve solution's convergency, a value of $1.0 \mathrm{kPa}$ was given to the cohesion $c^{\prime}$. Because of coupled stress-flow analyses, coefficient of conductivities were assigned to all soil layers (Tables 2 and 3).

As previously mentioned, the struts, slabs, and diaphragm walls were discretized using one-dimensional line elements. Lacking suitable field data related to their failure, these structural components were characterized as linear elastic. Tables 4 and 5 list the values of elastic parameters used in the characterizations of structural elements for sites 1 and 2 , respectively.

\section{Construction Sequence}

The site activities during construction are listed in Tables 6 and 7. Since time frames were not available, they were estimated based on regulations and laws for conventional

Table 2 Parameter values used in finite element analysis of Shilin Li-Ba Bailauhui Site (after [19])

\begin{tabular}{lllllllll}
\hline Depth $(\mathrm{m})$ & Soil type & $\gamma_{\mathrm{t}}\left(\mathrm{kN} / \mathrm{m}^{3}\right)$ & $K_{0}$ & $E(\mathrm{kPa})$ & $\nu$ & $k_{\mathrm{x}}, k_{\mathrm{y}}(\mathrm{m} / \mathrm{day})$ & $p_{\mathrm{o}}^{\prime}(\mathrm{kPa})$ & $\Phi^{\prime}\left({ }^{\circ}\right)$ \\
\hline $0-4.5$ & SM & 20.29 & 0.5 & $8.0 \times 10^{3}$ & 0.3 & $1.0,1.0$ & - & 30 \\
$4.5-8.7$ & ML-CL & 19.50 & 0.5 & $1.0 \times 10^{4}$ & 0.3 & $1.0,1.0$ & - & 30 \\
$8.7-10.7$ & SM-SP & 19.70 & 0.5 & $2.0 \times 10^{4}$ & 0.3 & $1.0,1.0$ & - & 30 \\
$>10.7$ & $\mathrm{CL}^{\mathrm{a}}$ & 18.82 & 0.5 & - & - & $6.9 \times 10^{-6}, 3.0 \times 10^{-7}$ & 214 & - \\
\hline
\end{tabular}

${ }^{a}$ Refer to Table 1 for clay material properties 
Table 3 Parameter values used in finite element analysis of Beitou Shipai Zi-Qiang street site (after [19])

\begin{tabular}{lllllllll}
\hline Depth $(\mathrm{m})$ & Soil type & $\gamma_{\mathrm{t}}\left(\mathrm{kN} / \mathrm{m}^{3}\right)$ & $K_{0}$ & $E(\mathrm{kPa})$ & $\nu$ & $k_{\mathrm{x}}, k_{\mathrm{y}}(\mathrm{m} /$ day $)$ & $p_{\mathrm{o}^{\prime}}(\mathrm{kPa})$ & $\Phi^{\prime}\left({ }^{\circ}\right)$ \\
\hline $0-1.5$ & Fill & 19.60 & 0.77 & $8.0 \times 10^{3}$ & 0.3 & $1.0,1.0$ & - & 30 \\
$1.5-5.5$ & $\mathrm{ML}$ & 19.60 & 0.77 & $1.0 \times 10^{4}$ & 0.3 & $1.0,1.0$ & - & 30 \\
$>5.5$ & $\mathrm{CL}^{\mathrm{a}}$ & 18.82 & 0.5 & - & - & $6.9 \times 10^{-6}, 3.0 \times 10^{-7}$ & 151 & - \\
\hline
\end{tabular}

${ }^{a}$ Refer to Table 1 for clay material properties

excavation according to the Construction and Planning Agency of the Ministry of the Interior, Public Construction Commission, and Taipei City Construction Management Office.

The simulated construction sequence for each site followed, as closely as possible, the actual one recorded in the field. The construction sequence for each site was simulated using "stage construction" loading inputs in PLAXIS, with a maximum of 250 time steps and an error tolerance of 0.010 specified. A realistic simulation of various excavation activities was realized by deactivating or reactivating loads, "volume meshes" or structural elements as created in the geometry input. The diaphragm wall was assumed to have been installed with negligible disturbance to the surrounding soils.

\section{Results of Simulations}

Simulated lateral soil deflections, ground surface settlements, wall bending moments, and strut forces are compared in this section. In these comparisons, the solid lines, dashed lines, and dotted lines represent the simulations obtained using the anisotropic non-associative, isotropic non-associative, and anisotropic associative versions of the enhanced bounding surface model, respectively.

Table 4 Parameters for Shilin Li-Ba Bailauhui site (after [20])

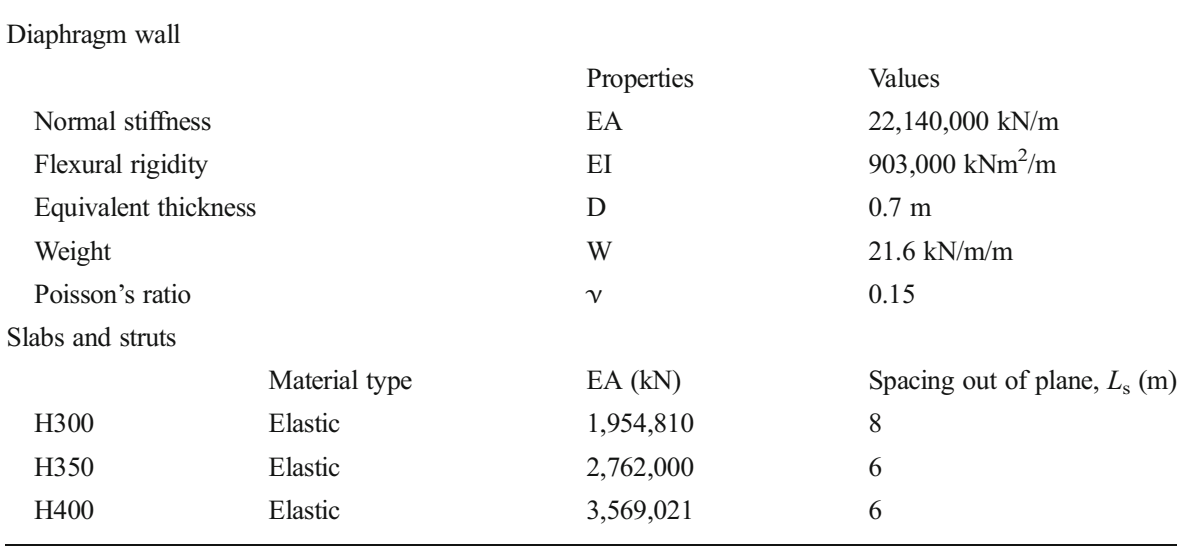


Table 5 Parameters for Beitou Shipai Zi-Qiang street site (after [20])

\begin{tabular}{llll}
\hline Diaphragm wall & & & \\
& Properties & Value \\
Normal stiffness & EA & $22,140,000 \mathrm{kN} / \mathrm{m}$ \\
Flexural rigidity & EI & $462,100 \mathrm{kNm} / \mathrm{m}$ \\
Equivalent thickness & $D$ & $0.5 \mathrm{~m}$ \\
Weight & $W$ & $21.6 \mathrm{kN} / \mathrm{m} / \mathrm{m}$ \\
Poisson's ratio & $\nu$ & 0.15 \\
Slabs and struts & & & \\
& Material type & EA $(\mathrm{kN})$ & Spacing out of plane, $L_{\mathrm{s}}(\mathrm{m})$ \\
$\mathrm{H} 300$ & $1,954,810$ & 8 \\
$\mathrm{H} 400$ & Elastic & $3,569,021$ & 6 \\
\hline
\end{tabular}

\section{Shilin Li-Ba Bailaohui (Site 1)}

Figure 4 shows the lateral soil deflection as a function of depth at site 1, obtained using the three different versions of the enhanced bounding surface model. As evident from this figure, very similar lateral deflections were predicted by the three versions of the model. From stage 6 to 7 the lateral displacement at the bottom of the wall increases by approximately $33 \%$. This rather large increase indicates that the finite element simulation is tending to some "ultimate" condition in which convergence may not be realized within the preset error tolerance of 0.010 . In short, the simulated response is tending towards "numerical failure."

Figure 5 shows the simulated ground surface settlement, obtained using three versions of the enhanced bounding surface model. The mode of deformation obtained using all versions of model is similar. In all three cases, the ground settlements progressively increase with each construction stage, especially following stage 5. However, since it predicts larger settlements than the two anisotropic versions, the isotropic version of the model gives more conservative results. The anisotropic versions of model show a settlement as large as $50 \mathrm{~cm}$, indicating possible large distortion in the building.

Table 6 Excavation sequence for Shilin Li-Ba Bailauhui site (after [19])

\begin{tabular}{lll}
\hline Stage & Duration (days) $^{\mathrm{a}}$ & Construction sequence \\
\hline 1 & - & Construct diaphragm wall \\
$1 \mathrm{a}$ & 10 & Excavate to elevation of $-1.8 \mathrm{~m}$ \\
2 & 30 & Install the 1st strut \\
3 & 15 & Excavate to elevation of $-4.35 \mathrm{~m}$ \\
4 & 30 & Install the 2 nd strut \\
$4 \mathrm{a}$ & 30 & Install the 3rd strut \\
5 & 20 & Excavate to elevation of $-7.65 \mathrm{~m}$ \\
$5 \mathrm{a}$ & 30 & Install the 4th strut \\
6 & 18 & Excavate to elevation of $-10.95 \mathrm{~m}$ \\
7 & 25 & Excavate to elevation of $-13.45 \mathrm{~m}$ \\
\hline
\end{tabular}


Table 7 Excavation sequence for Beitou Shipai Zi-Qiang street site (after [19])

${ }^{\mathrm{a}}$ Estimated based on regulatory agencies

\begin{tabular}{lcl}
\hline Stage & Duration (days) & Construction sequence \\
\hline 1 & - & Construct diaphragm wall \\
$1 \mathrm{a}$ & 10 & Excavate to elevation of $-1.9 \mathrm{~m}$ \\
2 & 30 & Install the 1st strut \\
3 & 11 & Excavate to elevation of $-4.2 \mathrm{~m}$ \\
$3 \mathrm{a}$ & 30 & Install the 2 nd strut \\
4 & 12 & Excavate to elevation of $-6.5 \mathrm{~m}$ \\
5 & 30 & Install the 3rd strut \\
6 & 15 & Excavate to elevation of $-9.3 \mathrm{~m}$
\end{tabular}

Figure 6 compares the lateral soil deflections at a distance of $10 \mathrm{~m}$ behind the wall, obtained using the three versions of the enhanced bounding surface model. These results are seen to be quite similar, which is consistent with the results shown in Fig. 4. Generally, the results obtained using the enhanced isotropic version of bounding surface model were more conservative than the two anisotropic versions.

The wall bending moments, obtained using the three versions of the enhanced bounding surface model, are presented in Fig. 7. These results indicate that the isotropic version of the bounding surface model generally gives slightly larger bending moments than the anisotropic versions of the model. This is consistent with the earlier observation that the isotropic version of the enhanced bounding surface model is more conservative in lateral displacements than the two anisotropic versions of the model.

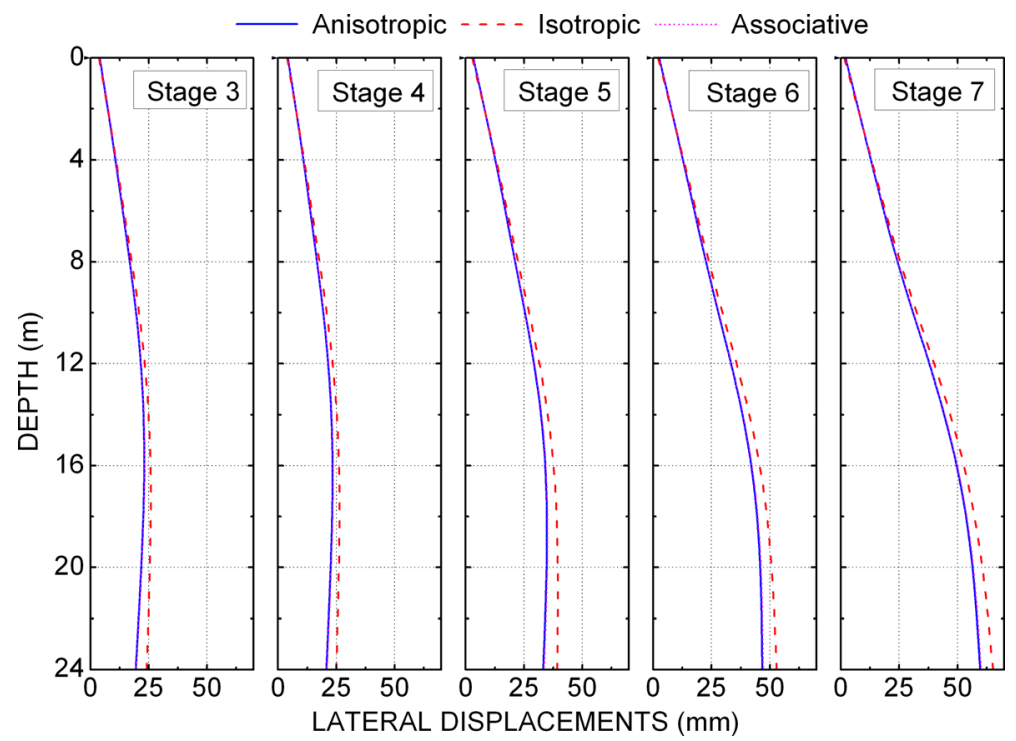

Fig. 4 Lateral wall deflection at site 1 


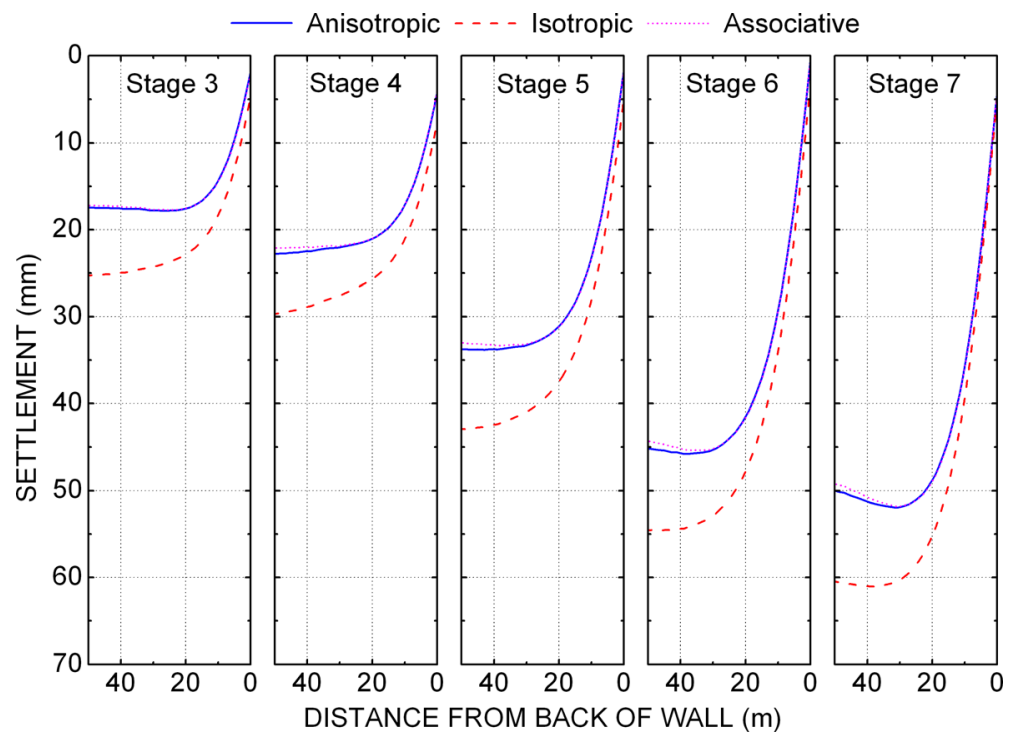

Fig. 5 Ground surface settlement at site 1

Figure 8 summarizes the strut forces acting in each stage of excavation using the different versions of the enhanced bounding surface model. All strut forces are compressive. In addition, similar trends for strut force development were observed for all three versions of the enhanced bounding surface model. Throughout the

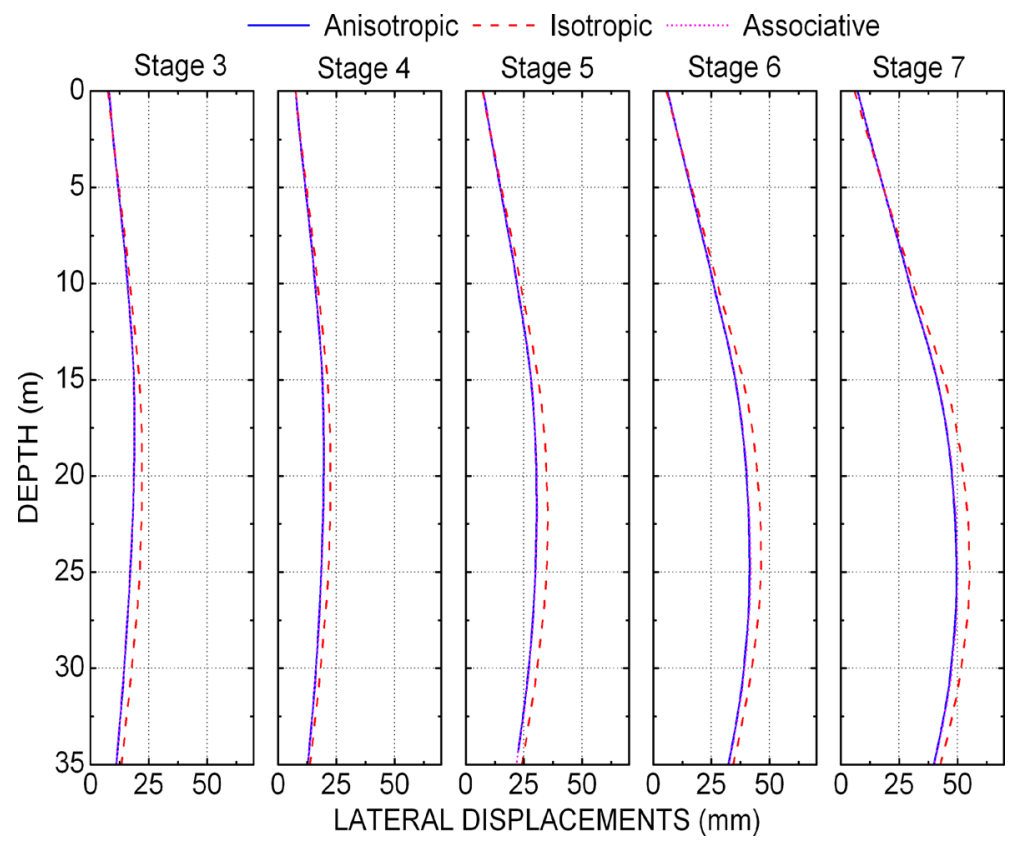

Fig. 6 Lateral soil deflection at $10 \mathrm{~m}$ behind the wall at site 1 


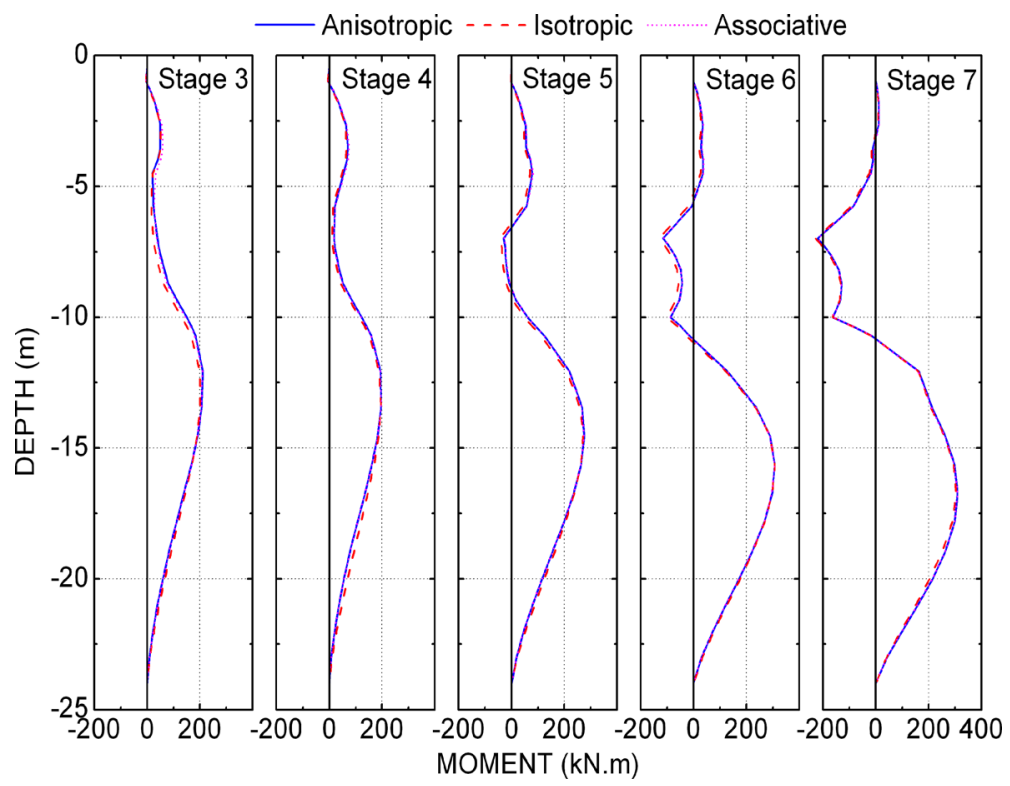

Fig. 7 Retaining wall bending moments at site 1

excavation there was a decrease in the near-surface supporting force. The highest supporting force, which occurred in stage 7 , was about $320.0 \mathrm{kN} \mathrm{m}$.

Figure 9 shows the shear strain distribution in the ground. The vicinity of excavation showed a larger concentration of shear strain. The results, such as that at stage 7 of excavation, show that larger shear strains are developed in the case of anisotropic

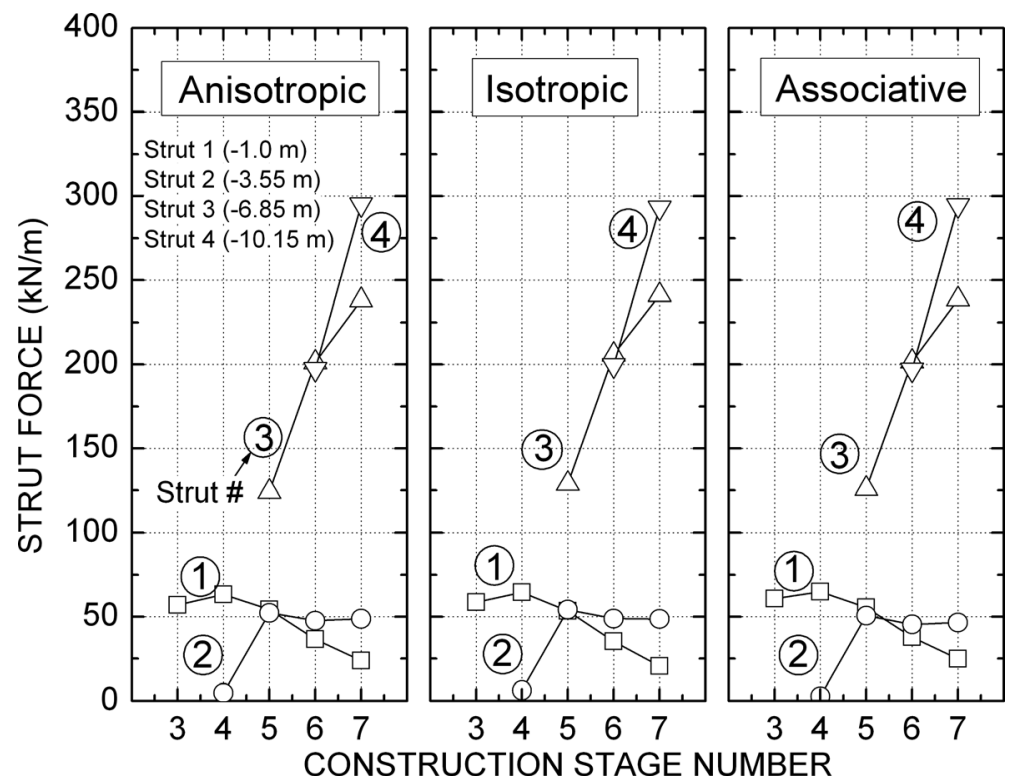

Fig. 8 Summary of strut force development at site 1 


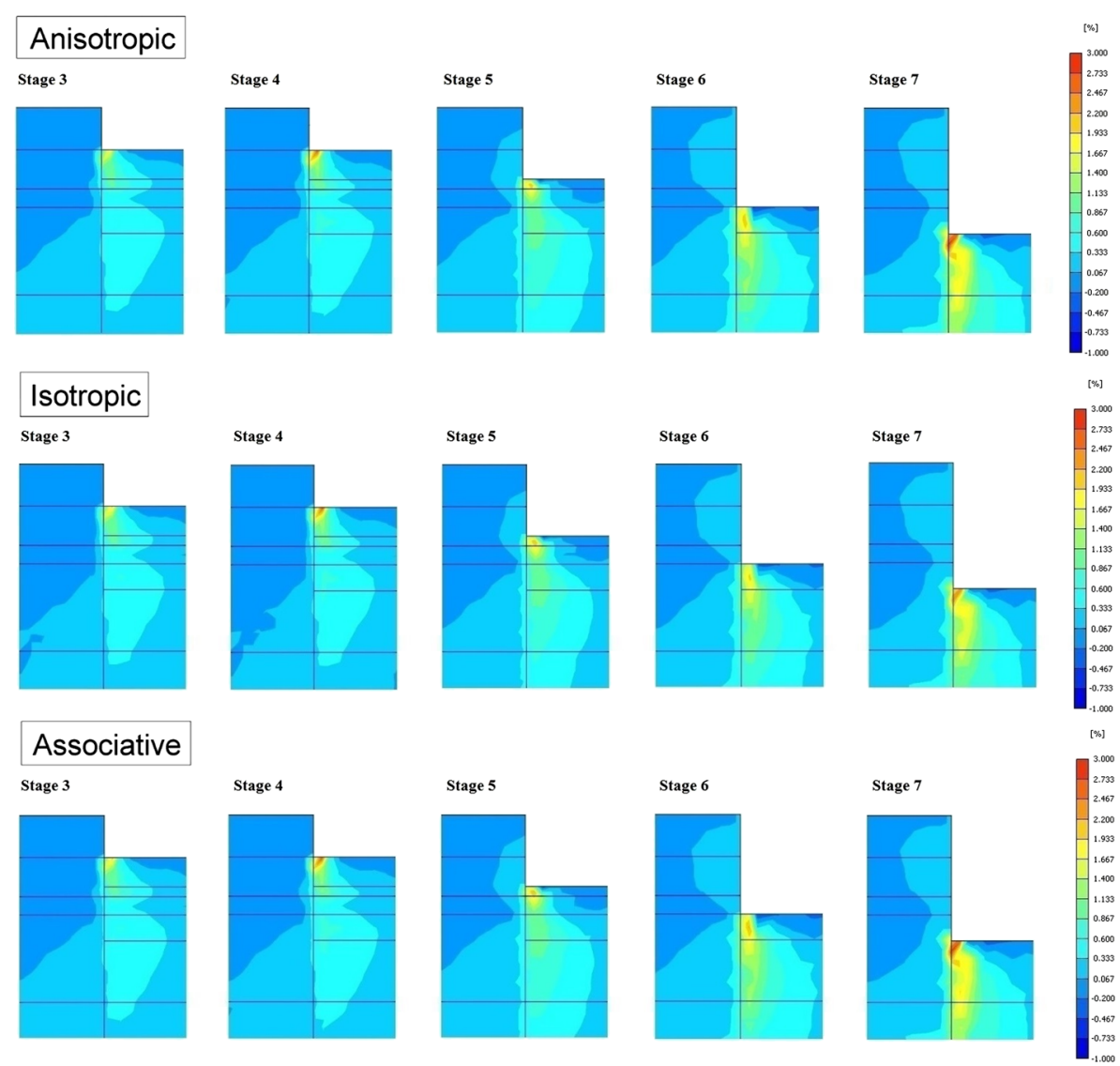

Fig. 9 Shear strain distributions at site 1

models compared to the isotropic model. The difference between the two anisotropic versions of model is not obvious.

\section{Beitou Shipai Zi-Qiang Street (Site 2)}

Figure 10 shows the lateral soil deflection versus depth at site 2, obtained using the three different versions of the enhanced bounding surface model. Very similar lateral deflections were predicted by the three versions of the model. The results showed that from stage 5 to stage 6 the lateral displacement at the bottom of the wall increases by approximately $50 \%$. This rather large increase again indicates (recall Fig. 4) that the finite element solution is not converging, i.e., it approaches "numerical failure."

Figure 11 shows the simulated ground surface settlement at site 2, obtained using all three versions of the enhanced bounding surface model. In all three cases, the ground settlements progressively increase, especially following stage 5 . At stage 6 , the settlements obtained exceed $60 \mathrm{~cm}$, indicating stability of excavation.

The wall bending moments, obtained using the three versions of the enhanced bounding surface model, are presented in Fig. 12. These results indicate that the isotropic version of the model again gives slightly larger bending moments than the 


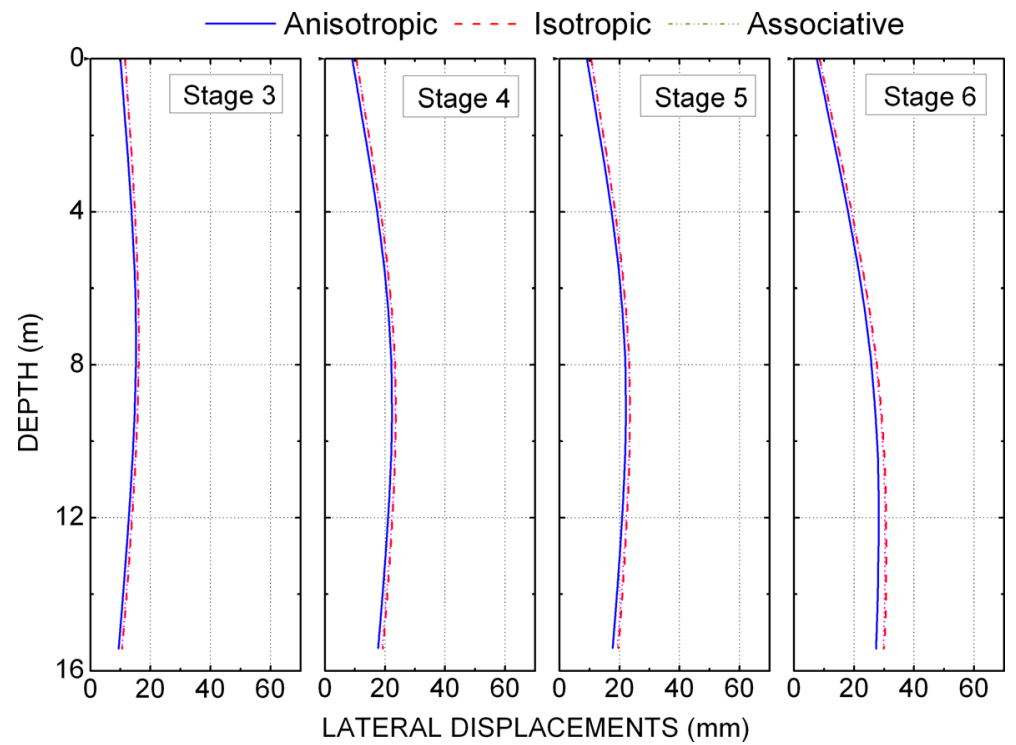

Fig. 10 Lateral wall deflection at site 2

anisotropic versions of the model. This is consistent with the earlier observation that the isotropic version of the enhanced bounding surface model is more conservative than the two anisotropic versions of the model.

Figure 13 summarizes the strut forces acting in each stage of excavation using the different versions of the enhanced bounding surface model. All strut forces are compressive. In addition, similar trends for strut force development were observed for all three versions of the enhanced bounding surface model. Throughout the excavation, there was a decrease in the near-surface supporting force. The highest

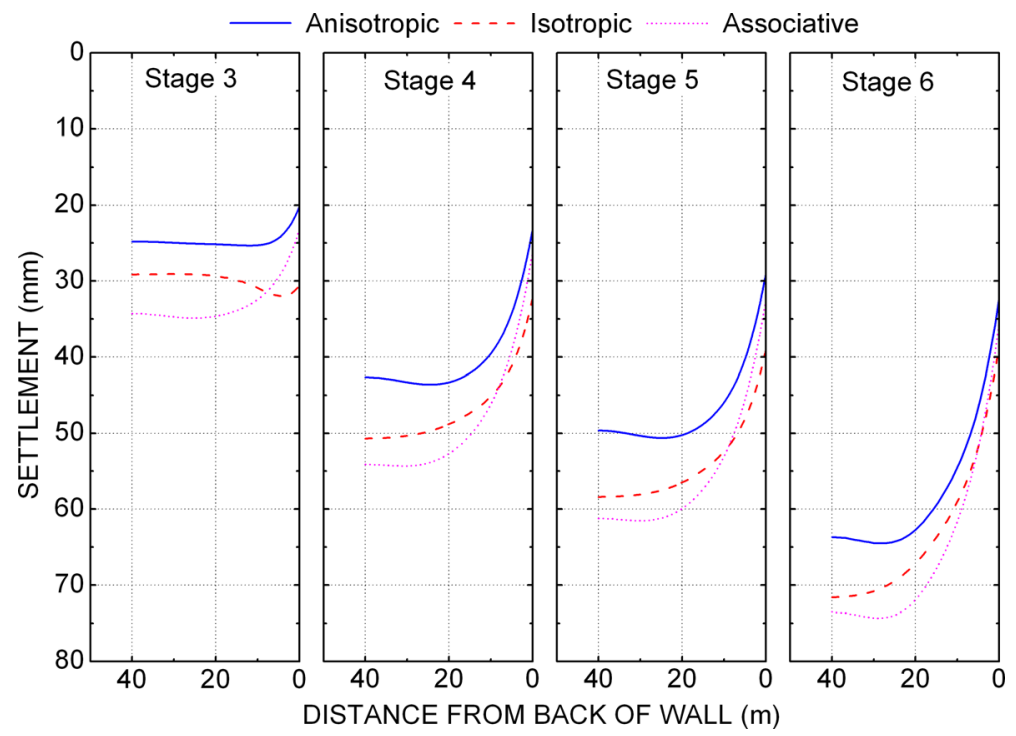

Fig. 11 Ground surface settlement at site 2 


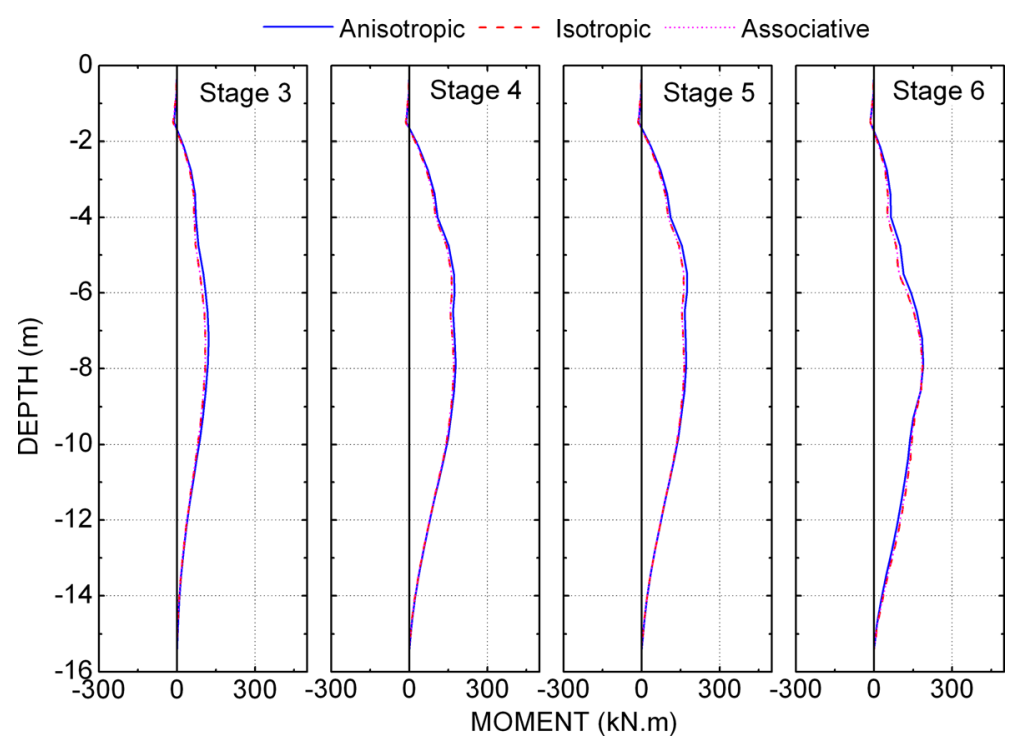

Fig. 12 Retaining wall bending moments at site 2

supporting force, which occurred in stages 4 and 5, was about $105.3 \mathrm{kN} \mathrm{m}$. Unlike site 1 , the highest supporting force was not obtained at the final stage. This indicates a potential for failure before reaching the final stage.

As shown in Fig. 14, the shear strain is more concentrated at vicinity of excavation. Similar to site 1, the anisotropic versions of soil model show a larger shear strain concentration compared to the isotropic version of model.

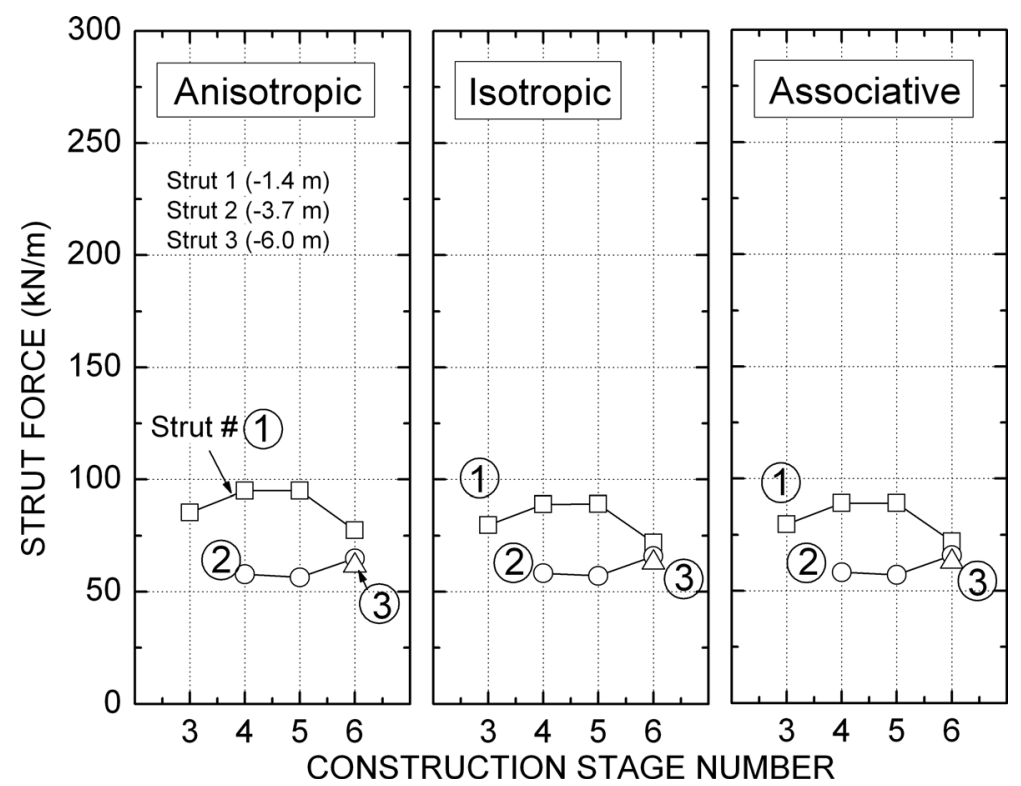

Fig. 13 Summary of strut force development at site 2 


\section{Anisotropic}
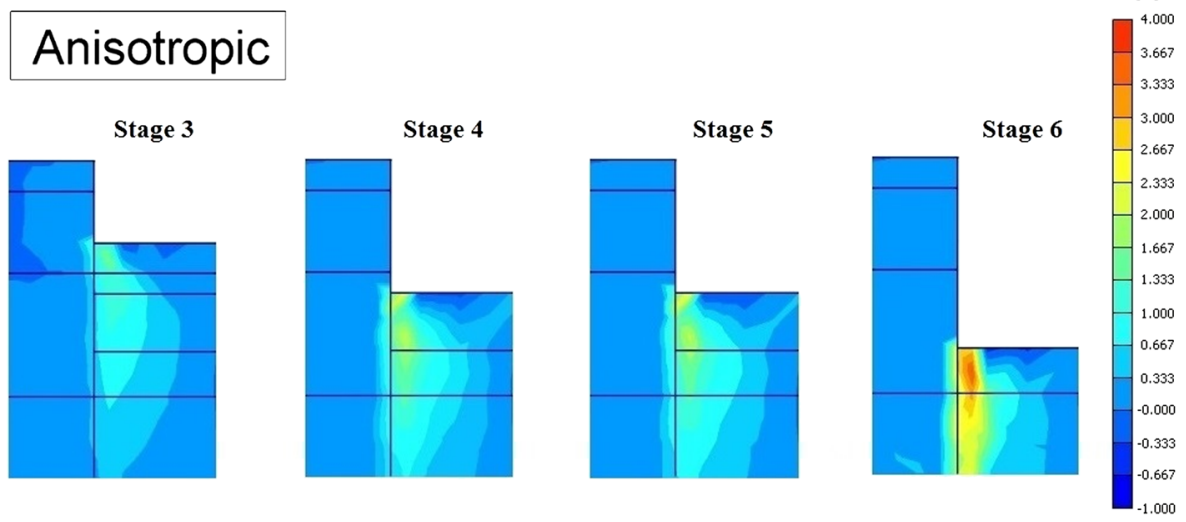

\section{Isotropic}

Stage 3

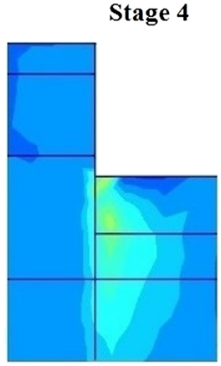

Stage 5
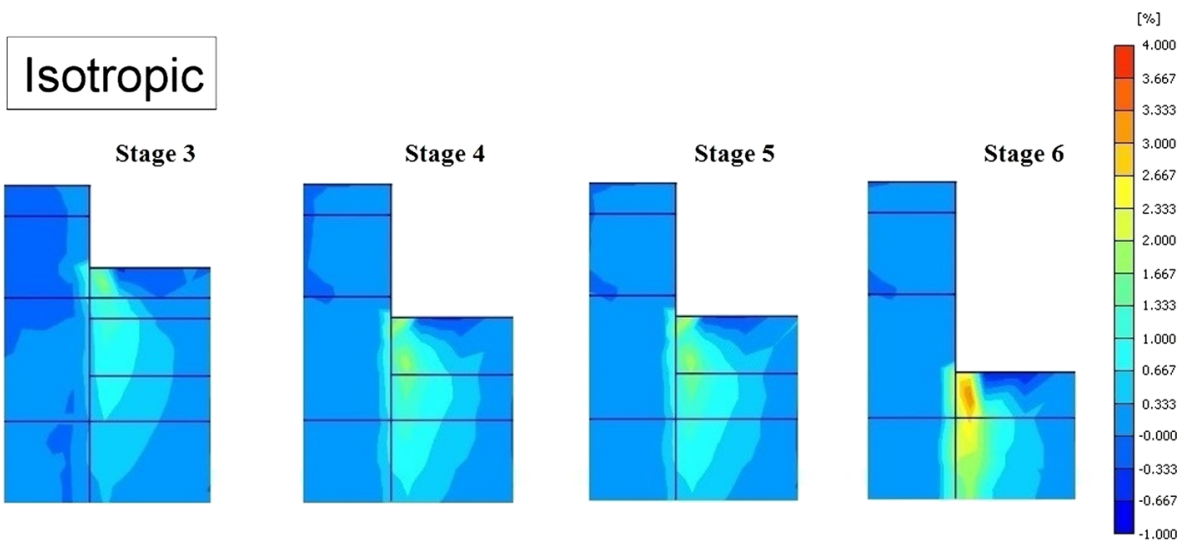

\section{Associative}

Stage 3

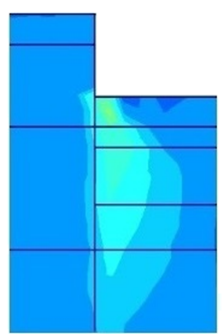

Stage 4

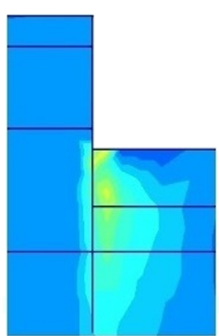

Stage 5

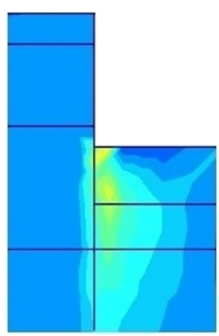

[\%]

1000

.333 .667 (1) .667 .000 06 .000 .667 $[\%]$

4.000 3.333 2667 .000 .667

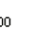
667

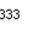
.

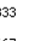
$-1.000$ [\%]

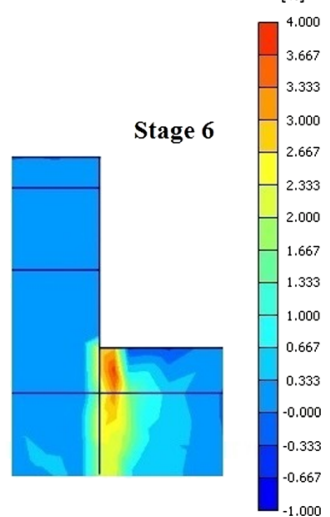

Fig. 14 Shear strain distributions at site 2

The simulated results indicate that, in the early stages of excavation, the ground displacements associated with a successful and a failed excavation were similar and consistent with each other. However, as the simulation continued to the final stage of excavation, a minor transition in the mode of lateral soil deflection and ground surface settlement could be observed. These results might have implications for possible 
failure. The results indicate the potential of applying the enhanced anisotropic bounding surface model in analyzing excavation failure sites, since soil softening behavior is accounted for in the analysis.

\section{Conclusions}

This paper described the simulation of two deep excavation case histories involving failure in soft cohesive soils. These soils were characterized by an enhanced anisotropic bounding surface model with associative [17] and non-associative [11, 12] flow rules. This model was implemented into the PLAXIS computer program [26] for the analyses.

Despite the fact that because of pending litigation there were no actual field results available against which to compare the present finite element simulations, the assessment of three different versions of the enhanced bounding surface model has been realized. The comparison of lateral deflections, ground surface settlements, retaining wall bending moments, and strut forces has provided insight into simulating deep excavations up to failure.

The following conclusions are based on the results of the simulations performed:

- The anisotropic non-associative, isotropic non-associative, and anisotropic associative versions of the enhanced bounding surface have the ability to realistically simulate deep excavations, possibly leading to possible collapse.

- In general, the results obtained using the aforementioned versions of the enhanced bounding surface model were quite similar. The difference between the anisotropic associative and non-associative versions of the model was small. However, before definite conclusions can be reached on this issue, additional finite element analyses of collapses and excessive ground movements associated with deep excavations need to be performed.

- The difference between the isotropic and anisotropic versions of the enhanced bounding surface model was much more significant than the difference between the anisotropic associative and non-associative versions of the model. In particular, the isotropic version of the model produced larger simulated lateral displacements, settlements, and bending moments. Consequently, the isotropic results were more conservative. The difference between the isotropic and anisotropic versions of the model was partially attributed to the lack of the anisotropic hardening rule in the former version of the model. Given the fact that behavior Taipei silty clay exhibits postpeak softening, it is generally preferable to use a non-associative flow rule.

This study has provided insight into the application of the enhanced anisotropic bounding surface model to analyze failure in excavations. Large lateral displacements and settlements are indicators of failure. Additional comparisons with monitored cases involving failure should be performed. To increase accuracy in these analyses, the behavior of cohesionless soils found at the sites should be characterized using more advanced constitutive models, such as Ling and Yang [16], instead of the more simplistic Mohr-Coulomb model used herein. This is, of course, predicated on the availability of suitable experimental data from which to calibrate such models. The 
limitations of PLAXIS, such as the small deformation assumption and the constraint of using linear elastic structural elements, should also be recognized.

\section{References}

1. Biot, M.A.: General solutions of the equations of elasticity and consolidation for porous material. J. Appl. Mech. 23, 91-96 (1956)

2. Chin, C.T., Cheng, T.Y., Liu, C.J.: Relationship between undrained shear strength and overconsolidation ratio of Taipei Silt. J. Chin. Inst. Civil Hydraul. Eng. 1(3), 245-250 (1989)

3. Clough, G., O'Rourke, T.: Construction induced movements of in-situ walls design and performance of earth retaining structures. ASCE Geotech. Spec. Publ. 25, 439-470 (1990)

4. Dafalias, Y.F.: Bounding surface plasticity. I: mathematical foundation and the concept of hypoplasticity. J. of Eng. Mech., ASCE 112(9), 966-987 (1986)

5. Dafalias, Y.F., Herrmann, L.R.: Bounding surface plasticity II: application to isotropic cohesive soils. J. of Eng. Mech., ASCE 112(12), 1263-1291 (1986)

6. Finno, R.J., Bryson, S., Calvello, M.: Performance of a stiff support system in soft clay. J. Geotech. Geoenviron. Eng. ASCE 128(8), 660-671 (2002)

7. Finno, R.J., Harahap, I.S., Sabatini, P.J.: Analysis of braced excavations with coupled finite element formulations. Comput. Geotech. 12(2), 91-114 (1991)

8. Goldberg, D. T., Jaworski, W. E. and Gordon, M. D. (1976). Lateral support systems and underpinning. Report FHWA-RD-75-128, Vol. 1, Federal Highway Administration, Washington, D. C.

9. Hsieh, P.G., Ou, C.Y., Liu, H.T.: Basal heave analysis of excavations with consideration of anisotropic undrained strength of clay. Can. Geotech. J. 45(6), 788-799 (2008)

10. Hung, C., Jiang, J., Ling, H. I. and Kaliakin, V. N. (2011). Calibration of Taipei silty clay using an enhanced anisotropic elastoplastic bounding surface model. Proceedings of the Fifth International Symposium on Deformation Characteristics of Geomaterials, 478-482.

11. Jiang, J.H., Ling, H.I.: A framework of anisotropic elastoplastic model for clays. Mech. Res. Commun. 37, 394-398 (2010)

12. Jiang, J.H., Ling, H.I., Kaliakin, V.N.: An associative and non-associative anisotropic bounding surface model for clay. J. Appl. Mech. 79(3), 031010-10 (2012)

13. Kaliakin, V.N.: A simple computer program for assessing the idiosyncrasies of various constitutive models used to characterize soils. Dept. of Civil Engineering Report, University of Delaware, Newark, DE (1992)

14. Kaliakin, V.N., Dafalias, Y.F.: Simplifications to the bounding surface model for cohesive soils. Int. J. Numer. Anal. Methods Geomech. 13(1), 91-100 (1989)

15. Kung, G.T.C. (2010). Finite element analysis of wall deflection and ground movements caused by braced excavations. Finite Element Analysis, David Moratal (Ed.), Sciyo.

16. Ling, H.I., Yang, S.: A unified sand model based on critical state and generalized plasticity. J. of Eng. Mech., ASCE 132(12), 138-1391 (2006)

17. Ling, H.I., Yue, D., Kaliakin, V.N., Themelis, N.J.: An anisotropic elastoplastic bounding surface model for cohesive soils. J. of Eng. Mech., ASCE 128(7), 748-758 (2002)

18. Liu, C. C. (1999). A generalized effective stress constitutive model for Taipei clay. Ph.D. Dissertation, National Taiwan University of Science and Technology, Taipei, Taiwan.

19. Liu, H. T. (2004). A study of basal heave analysis of excavation based on anisotropic soil strength. M.S. Thesis, National Taiwan University of Science and Technology, Taiwan

20. Liao, H. J. and Ou, C. Y. (2009). Deep Excavation-Theory and Practice, Scientific \& Technical Publishing Co., Ltd.

21. Osami, A.E., Clough, G.W.: Pore-pressure dissipation during excavation. J. Geotech. Eng. Div. ASCE 105(4), 481-498 (1979)

22. Ou, C.Y., Lai, C.H.: Finite-element analysis of deep excavation in layered sandy and clayey soil deposits. Can. Geotech. J. 31(2), 204-214 (1994)

23. Ou, C.Y., Liao, J.T., Lin, H.D.: Performance of diaphragm wall constructed using top-down method. J. Geotech. Geoenviron. Eng. ASCE 124(9), 798-808 (1998)

24. PCC: Chapter 6: foundation and construction. PCC article, c6c-6-2-6 page 61. Public Construction Commission, Taiwan (2007) 
25. Peck, R. B. (1969). Deep excavation and tunneling in soft ground. Proceedings of the Seventh International Conference on Soil Mechanics and Foundation Engineering, State of the art Volume, 7(3), 225-290

26. Plaxis: Reference and material models manuals. Plaxis, Netherlands (2012)

27. Siddiquee, M.S.A., Tanaka, T., Tatsuoka, F., Tani, K., Morimoto, T.: Numerical simulation of bearing capacity characteristics of strip footing on sand. Soils Found. 39(4), 93-109 (1999)

28. Whittle, A.J., Hashash, Y.M., Whitman, R.: Analysis of deep excavation in Boston. J. Geotech. Eng. 119(1), 69-90 (1993)

29. Yong, K.Y., Lee, F.H., Parnploy, U., Lee, S.L.: Elasto-plastic consolidation analysis for strutted excavation in clay. Comput. Geotech. 8(4), 311-328 (1989) 